\title{
Proposing Alternative Masters Degrees Models for Small Colleges/Schools of Business
}

\section{Keller GF*}

Eastern Oregon University, One University Blvd. Zabel Hall 209, La Grande, OR, USA

\begin{abstract}
Over the past two decades, the number of institutions offering Masters of Business degrees has expanded to meet market demand. The sheer expansion has created what it would describe as a red ocean. As more small colleges/ schools of business enter the Masters Business degree marketplace, the inevitable decisions of how to attract customers and make a profit must be made; thus, the unconscious plunge into the Masters Business degree red ocean (look alike curricula and price sensitive tuition) is made. Must small colleges/schools of business that compete in a red ocean accept the predictable mediocre return on their investment/energy? This paper offers alternative Masters in business models for small colleges/schools of business. Alternate specialized business accreditation pathways, eight foundation principles and seven distinctive curricula are proposed to renew and create a fresh competitive advantage for small business college/schools. The end state is freedom from the Masters Business degrees red ocean.
\end{abstract}

Keywords: Innovative master's; Business degree program; Blue ocean strategy; Specialized accreditation

\section{Introduction}

Over the past two decades, the number of institutions offering Masters of Business degrees in a variety of modalities has expanded to meet market demand. From 2011-2012, “191,571 people graduated from U.S. schools with advanced degrees in business, some $25.4 \%$ of all the master's degrees conferred [1]. That compares with 178,062 master's degrees in education, or $23.6 \%$, of all the advanced degrees" [2]. The sheer enlargement of the number of MBA program offerings has created what Kim and Mauborgne [1] would describe as a red ocean. In a red ocean environment, a proliferation of competitors exists and the nature of the red ocean business strategy is to beat the competition (or at least gain a fraction of the existing marketplace), exploit existing demand and compete nearly exclusively on price. As more small colleges/schools of business [3] as having fewer than 5,000 students) enter the Masters marketplace, the inevitable decisions of how to attract customers and make a profit must be made; thus, the unconscious plunge into the masters red ocean is performed. Must the inevitable product offering for small colleges/schools of business that compete in a red ocean to deploy a variation of a red ocean marketing/ operational strategy and accept the predictable mediocre return on their investment/energy? This paper suggests some alternatives to business strategies as usual for small colleges/schools of business that desire to take a different tactic when contending in the Masters of Business bazaar.

\section{Is specialized Accreditation Necessary?}

A common path that many small colleges/schools of business take when offering masters business degrees is to secure specialized accreditation from the AACSB, ACBSP or IACBE for the college/ school. The purposes for accreditation are numerous including marketing appeal, faculty recruiting, leverage for internal university resources, recognition as an elite institution and etc. [4]. It could be argued that "just as regional accreditation became the standard for universities in the 1950s, specialized accreditation is the standard for schools of business in the 2000s" [5].

Institutional leaders must query the motivation for pursing a specialized accreditation distinction. If accreditation is designed to enhance the business degree programs' marketing appeal (essentially seeking parity with others in the red ocean) or for internal institutional maneuverings, the time, energy and short and long-term costs for the effort may delay or detract from creating a blue ocean Masters business program. Kim and Mauborgne [6] define a blue ocean as a market space where "demand is created rather than fought over. There is ample opportunity for growth that is both profitable and rapid". One prominent question institutional leaders should discuss when seeking accreditation is this; will the accreditation credential will provide greater benefits to the college/school compared to the perceived value of the customer or the customer's employer?

Several substitutions for traditional academic specialized accreditation are available for reflection that may simultaneously lend professional and marketing credibility to the small college/ school's master's business programs and create a blue ocean opening. Two world class sources for certification contemplation are the American Society for Quality (ASQ) and the International Standards Organization (ISO). Ponder the instant recognition that both entities invoke among industry groups, employers and those seeking a business degree that offers a distinctive competitive advantage. Additionally, both the ASQ and ISO have global "brand" recognition. This quality acknowledgment would enable small colleges/schools to confidently extend their Masters Business programs beyond local, regional or national boundaries while simultaneously gaining the recognition of quality/practicality of employers. The instant acknowledgement of respected global industry accrediting quality [organizations not only would provide the program's graduates, faculty and recruiting efforts (students and faculty) with a unique "endorsement" but also provide the school/college with a marketing leadership position-"the only MBA program in the locale/region to be certified by the ISO or ASQ."

${ }^{*}$ Corresponding author: Keller GF, Department of Business Management, Eastern Oregon University, One University Blvd. Zabel Hall 209, La Grande, OR 97850-2807, USA, Tel: 5419623672, 8004528639; E-mail: gkeller@eou.edu

Recieved March 21, 2018; Accepted April 18, 2018; Published April 26, 2018

Citation: Keller GF (2018) Proposing Alternative Masters Degrees Models for Small Colleges/Schools of Business. J Entrepren Organiz Manag 7: 232. doi: 10.4172/2169-026X.1000232

Copyright: () 2018 Keller GF. This is an open-access article distributed under the terms of the Creative Commons Attribution License, which permits unrestricted use, distribution, and reproduction in any medium, provided the original author and source are credited. 
Finally, a college/school could seek to be "compliant" with their choice of an academic specialized accreditation entity or ISO/ASQ to avoid the cost and, to an extent, restraints that complete certification require. The primary advantages of the compliance strategy are not only cost reductions but the ability of a college/school to make programmatic changes at its discretion rather than needing and waiting for the approval of any of the above accrediting organizations. The ISO/ ASQ certification provides a college/school with an exclusive brand positioning advantage compared to larger or legacy competitors and is a step in the creation of a local/regional/online blue ocean.

\section{Innovation for the Small Masters Business Program}

Defining and determining which Masters Business programs are innovative is an art. What one institution, dean or faculty may consider pioneering others may dismiss as unworthy of attention or serious consideration. Consider that the first MBA program taught exclusively by academicians or first online MBA program offerings were dismissed or marginalized by the academic community. Given the inherent risk adverse nature of small college/schools to jeopardize a steady source of students and revenue with their current "proven" programs, many institutions resign themselves to compete in the Masters business red ocean.

Byrne [7] offered some insight into the characteristics of innovative MBA programs. Some of the noted attributes of groundbreaking programs ranged: from the unique and novel growth and scaling initiative at Northwestern University's Kellogg School of Management to the University of Illinois' bold decision to launch a $\$ 20,000$ online MBA program based entirely on massive open online courses (MOOCs). In fact, the majority of the most impressive business school innovations are built on technology. They include Harvard Business School's creation of the classroom of the future, an idea that borrows as much from TV broadcasting as it does from old fashioned classroom teaching, as well as the ongoing effort by William \& Mary's Mason School of Business to crowdsource a curriculum review that will lead to an overhaul of its MBA program.

Rampton [8] created a list of the 15 Most Innovative MBA Programs. Rampton's criteria were those MBA programs that "understand the importance of entrepreneurship and innovation through courses that can take students across the world and deliver critical thinking skills". Rampton's list contains the names of the usual high end MBA programs ranging from the Harvard Business School to Case Western Reserve's Weather head School of Management.

There are many clever arguments that a small college/school can make to maintain the status quo. The strongest case for preserving a small college/school's existing state of affairs in the Masters red ocean is the assertion that those cited by Rampton have the luxury of taking risk. As stated above, small college/schools tend to be conservative when making changes to a consistent, profitable MBA programs. However, they do so at their own peril. Once an MBA program is established (regardless of modality), it has become a part of the food chain in a red ocean. The claim that a small college/school program cannot "compete" with the top MBA programs is specious. Once an MBA program is established (regardless of modality) the college/school's leadership has either consciously or worse, unconsciously, chose to become a component of the red ocean food chain. Survival in a red ocean is possible, maybe even comfortable for a while; however, inevitably the need to adapt to survive will emerge. The general "remodeling" of MBA programs usually involves catching up with those who were willing to break from the accepted models; consider the Wharton School was created in 1891. Small colleges/schools can pursue a different route.

\section{Some Suggestions for a New Master's Model}

Eight principles are the foundation for renewing a small college/ school's Masters Business program. The end state is

Freedom from the Masters Business red ocean. The eight principles are:

\section{Renewal principle 1: Major MBA curricula change is occurring}

The Association to Advance Collegiate Schools of Business (AACSB) estimates that $75 \%$ of business schools have made some changes to their curricula. The leading MBA programs (Yale, Stanford, and Wharton) are de-emphasizing traditional disciple-based courses... in favor of a focus on leadership skills, innovation, social responsibility and a global perspective [9].

\section{Renewal principle 2: Creative destruction of MBA curricula}

"In many instances, you are seeing them (MBA curricula) being destroyed and rebuilt" [9].

\section{Renewal principle 3: Preparing students for businesses that don't exist}

According to Wharton Dean Thomas Robertson "Today they (business leaders) work in hedge funds and biotechnology... None of that existed 20 years ago" [9].

\section{Renewal principle 4: There is no best curriculum}

\section{Renewal principle 5: There are only the best curricula}

\section{Renewal principle 6: MBA programs exist in a crowded marketplace}

"The problem, it seems, is the proliferation of B-grade B-schools. Universities are now conferring 74 percent more business degrees than they did in the 2000-2001 school year. Much of that torrid growth has been driven by part-time and executive MBA programs at less-thanprestigious institutions looking to cash in. And while the supply of business grads has continued to grow, the WSJ finds that pay for young MBAs has dipped $4.6 \%$ since the recession, reflecting both the slow job market, and the fact that the degree seems to have lost some of its cache" [10].

\section{Renewal principle 7: Demand for MBAs \& MSs has not declined}

Over the long term the total number of business master's degrees (MBA plus MS) awarded each year by U.S. schools has grown rapidly, from 26,000 in 1970 to 168,000 in 2009.

But growth in recent years has been in one-year Specialized Master of Science (MS) degrees in business, while traditional two-year MBA degrees have leveled off [11].

Renewal principle 8: The blue ocean strategy was the inspiration of this alternative model

Red ocean strategy: Red ocean strategy includes:

- Compete in existing market space.

- Beat the competition.

- Exploit existing demand. 
- Make the value/cost trade-off.

- Align the whole system of a company's activities with its strategic choice of differentiation or low cost.

\section{Blue ocean strategy}

- Create uncontested market space.

- Make the competition irrelevant.

- Create and capture new demand.

- Break the value/cost trade-off.

- Align the whole system of a company's activities in pursuit of differentiation and low cost.

\section{The New Model}

As noted above, there is no best curriculum. A small college/school has an advantage over larger organizations. The clandestine enabler for a small college/school is the ability to change quickly, secure the initial lead and continue to transform as competitors from the Masters business red ocean emerge to imitate the first mover's proposition.

\section{Masters in Business Programs-Distinctive Curricula $(1+1=7)$}

In the proposed model the small college/school would offer two Masters Degrees with seven options.

1. MBA -Traditional (existing curriculum with refurbishments) and use of existing delivery and cohort model.

2. My MBA-A personalized MBA

3. MBA-Fast Track-An accelerated completion format

4. MBA-Online

5. MSM-Traditional (existing curriculum with refurbishments) and use of existing delivery and cohort model.

6. MSM-Online

7. My MSM-Personalized

Option 1: MBA-Traditional (continue to use the college/program's existing curriculum with refurbishments) and use of existing delivery model. In many cases the "traditional" model is a face to face, cohort structure. While the existing MBA program may be the "bread and butter" for the small college/school, a renewal is recommended not simply to refresh it but also significantly improve it with changes such as:

- Introduction of an "onboarding” Friday night-Saturday seminar the weekend before the first MBA course begins. The seminar would familiarize new Masters Students to the curriculum, each other and faculty, grading, quality expectations and other operational components of the program including the selection of their thesis or capstone project topic.

- Integration of a toll-gate process into the MBA Traditional curriculum to evaluate student fit and potential to successfully complete program requirements.

- Assignment of a Faculty Counselor to each student.

- An analysis of course sequencing should be made in partnership with curriculum subject matter experts (i.e., the College of Education) to determine if the existing MBA course arrangement facilitates or hinders learning and knowledge retention.

- All courses should be reviewed to ensure that the competencies and desired characteristics used to admit students are infused into each course and can be measured and evaluated.

- An exclusive MBA pre/post survey should be included in each course to measure the degree of learning that student's report they experienced during each course.

- An annual evaluation of the data derived from the toll-gate assessment process, grades and pre/post surveys should be conducted to determine if this MBA curriculum, faculty members and students are achieving the goals of the program.

Options 2-4: (2) My MBA-A personalized MBA, (3) MBAFast Track-An accelerated completion format and (4) MBAOnline

- The key component of MBA Choices 2-4 is a Common Competency Platform.

- The Common Competency Platform for the new MBA options consists of the following courses:

1. Management and Leadership: Key Similarities, Desirable Differences

2. Contemporary Financial Analysis

3. Understanding and Unleashing Creativity

4. Business Endurance Principles

5. Personal and Professional Ethics.

Note: No separate courses to write the thesis are included in the new options. A major introspective paper and Power Point presentation presented to a two-three-person faculty member committee would replace the thesis requirement.

Once the Common Competency Platform is completed; students in the new MBA programs (options 2-4) would select 4 of the following courses (examples-not an inclusive list) to complete their degree requirements; with approval of their Faculty Counselor and the MBA Director

1. Crisis Preparation and Disaster Management

2. Anticipating, Locating and Deciphering Problems

3. Critical Thinking Proficiency-From Data to Information to Decisions

4. Blue Ocean Strategy

5. National and Global Value Chain/Logistics Management

6. Great Management Literature-Wisdom from Classics and Great Thinkers

7. Historical and Contemporary Affairs-Understanding global cultures, societies, governments, legal developments, events and trends

8. Technological and Social Trends and Their Impact on Consumers

9. Agribusiness and Natural Resources Management 
10. Organic Agriculture Business Development

11. Talent Acquisition, Development, Retention and Deployment

12. Female Leadership Evolution-From Senior Executive to CEO to the Boardroom

13. Generating Profits from "the Bottom"-Profitable Business in Developing Countries

14. Comprehending and Utilizing Traditional and New Media

15. Psychology, Demographics, Economics and Statistical Tools to Navigate Future Trends

16. Thriving in a Minority/Majority America and World.

New MBA Product Lines From one product offering to "Brand Extension": Options 3-4: MBA-Fast Track, MBA-Online

- My MBA-Personalized: The My MBA curriculum is designed to offer a segment of EOU MBA students with course and specialization options that most small college/schools cannot realistically offer (example strategy simulation, econometrics, advanced IT and etc.).

- My MBA students would be required to take the Common Competency Platform in either a face to face or online format.

- After completing the Common Competency Platform requirement, the student could enroll in 4 Massive Open Online Courses (MOOCs) offered by academically qualified universities (ex. Harvard, Yale, MIT, and etc.) as determined by college/school's faculty/administration.

- The small college/school would create an independent study course sequence to accommodate the personalized My MBA option. The student, with consultation and under the direction of a Faculty Counselor, would "audit" Massive Open Online Course (MOOC) classes that would qualify as part of the personalized degree and complete assignments created by the appropriate faculty member.

\section{Option 3: MBA-fast track (an accelerated completion format)}

- The MBA Fast Track degree is designed to offer an MBA to those ready, willing and able to complete their degree requirements in 8-9 months.

- This degree is presented in a face-to-face modality and offered in the following sequence:

- After the "onboarding" Friday night-Saturday seminar the weekend before the first course begins is completed, a precourse assignment is assigned by the faculty member due before the first week of the course start.

- Common Competency Platform classes are offered in 2 week blocks; each class meets Monday-Friday (6:00 PM-10:00 PM) and on Saturday, 1:00 PM-5:00 PM), Sunday is a free day. During the class week, a group project is required. Upon completion of each course a final assignment is due 15 days after the course end.

- After a one month pause the next sequence of classes is conducted to complete the Common Competency Platform.

- After the Common Competency Platform is complete, students are free to enroll in the new curricula courses or Personalized Degree.
MBA-Fast Track Sequence Example

Start date: Month 1.

- Week 1: Onboarding weekend-Begin preparations for lead in assignment for first course and reading material.

- Week 2: Course 1 (submit leading assignment), attend classes; work on team project, complete course.

- Week 3: Course 2 (repeat requirements as noted for Course 1).

- One month break, time to complete trailing assignments and prepare for next pair of courses.

The one exception to the 2-week course sequencing format is for Contemporary Financial Analysis which would be the only course scheduled over a 2- week period.

\section{Option 4: MBA-online}

The MBA Online offering would follow any of the curricula format offerings noted above thus providing the small college/program more curricula options to offer than its typical local/regional competitors.

\section{Master's degree-masters in the science of management}

- Logic-Diversification of Master's Degree product offerings.

- A growth degree-open up not-for-profit sector and nonquantitative oriented managers.

- Facts: Growth in recent years has been in one-year Specialized Master of Science (MS) degrees in business, while traditional two-year MBA degrees have leveled off [11].

$\checkmark$ MSM Degree: Speed provides the competitive advantage

$\checkmark$ The MSM should follow the MBA Fast Track model and online platforms as they offer the speed to completion feature.

$\checkmark$ The key differences between the MBA and MSM will be admission requirements, content of two of the Common Competency Platform courses and selection the specialty options.

$\checkmark$ Students from a variety of backgrounds can migrate to the area that they wish to upgrade their skills or learn new management skills.

\section{Masters in the science of management degree options}

Three New Degree Options-MSM-Traditional (existing curriculum with refurbishments) and use of existing delivery and cohort model, MSM-Online and

\section{My MSM-Personalized.}

- Key competitive MSM advantage-one year or less degree completion-no thesis.

- Ability to attract individuals who do not have management experience compared to MBA degree.

- Build on the Common Competency Platform similar to the MBA degree.

- Use essentially the same Common Competency Platform MBA courses:

1. Management and Leadership: Key Similarities, Desirable Differences 
Citation: Keller GF (2018) Proposing Alternative Masters Degrees Models for Small Colleges/Schools of Business. J Entrepren Organiz Manag 7: 232. doi: 10.4172/2169-026X.1000232

Page 5 of 5

2. Contemporary Financial Analysis

3. Understanding and Unleashing Creativity

4. Business Endurance Principles

5. Personal and Professional Ethics.

Note: No separate course to write the thesis will be included in the new options. A major introspective paper and Power Point presentation presented to a two-three-person faculty member committee would replace the thesis requirement. This activity would be a graduation requirement and be included in the student's MSM fees.

MSM Students Select 4 of the Course Options to Complete/ Specialize (non-inclusive).

1. Crisis Preparation and Disaster Management

2. Anticipating, Locating and Deciphering Problems

3. Critical Thinking Proficiency-From Data to Information to Decisions

4. Blue Ocean Strategy

5. Management of Non-Profit Agencies

6. Great Management Literature-Wisdom from Classics and Great Thinkers

7. Historical and Contemporary Affairs-Understanding global cultures, societies, governments, legal developments, events and trends

8. Technological and Social Trends and Their Impact on Consumers

9. Talent Acquisition, Development, Retention and Deployment

10. Female Leadership Evolution-From Senior Executive to CEO to the Boardroom

11. Comprehending and Utilizing Traditional and New Media

12. Thriving in a Minority/Majority America and World

13. Marketing Strategies for Not-for-Profit enterprises.

14. Managing Family Owned Businesses

15. Protecting Intellectual Property

16. Not-for-Profit Agency Revenue Diversification

17. Managing Religious/Spiritually Based Organizations.

\section{Conclusion}

This presentation of alternative models for Masters Degrees for small colleges/schools of business is designed to create a blue ocean space and break out of the existing Masters Business red ocean. The key advantages to the expanded Masters products include:

1. MBA/MSM enrollment not reliant on the traditional university/ college enrollment funnel.

2. Creation of new product space rather than competing for a small share in a crowded market.

3. Protect and grow the small college/school's MBA program equity and brand.

4. Create additional revenue streams-degree upgrades, summer institutes, and constantly evolving new program offerings.

5. Demonstrate the value generation capacity of a small college/ school to leverage its faculty and capital resources to serve the unique needs of the small college/school's service area.

A small college/school does not have to implement all of the components noted in the above models simultaneously. Rather, the model offers the flexibility to implement the changes incrementally to allow the small college/school to scale up faculty, online technology capacity and related "back-office" requirements to meet increased enrollment. However, the model provides a low-risk opening to break away from the red ocean in which it currently competes.

\section{References}

1. Kim WC, Mauborgne R (2015) Blue ocean strategy. Harv Bus Rev.

2. Byrne $\mathrm{J}$ (2014) Why the MBA has become the most popular master's degree in the U.S.

3. CollegeData (2016) College size: small, medium or large?

4. Roller R, Andrews B, Bovee S (2003) Specialized accreditation of business schools: A comparison of alternative costs, benefits and motivations. J Educ Bus 78: 197-204.

5. Tullis KJ, Camey JP (2007) Strategic implications of specialized business school accreditation: End of the line for some business education programs? J Educ Bus 83: 45-51.

6. Kim WC, Mauborgne R (2004) Blue ocean strategy. Harv Bus Rev 82: 76-84.

7. Byrne J (2015) Most innovative business school ideas of 2015.

8. Rampton J (2015) The 15 most innovative MBA programs.

9. Loftus M (2011) Reinventing the MBA.

10. Weissmann $J$ (2013) There are officially too many MBAs.

11. Yeaple R (2012) Is the MBA obsolete? 